\title{
Federalismo e endividamento subnacional: uma discussão sobre a sustentabilidade da dívida estadual
}

\author{
MÔNICA MORA E FABIO GIAMBIAGI*
}

Federalism and subnational debt: a discussion on the sustainability of state debt. The subnational debt in Brazil was marked by successive bailouts by the federal government. The path of subnational debt induced some locals and state authorities to claim for further renegotiations. More specifically, some governors and mayors demanded a revision of the refinancing contracts. This article intends to present arguments sustained by simulations of the evolution of the path of the subnational debt, denying the necessity of changes in legal framework, which rules the state debt. The first section consists of a brief overview. The following section treats the institutional framework designed to safeguard the fiscal intertemporal balance. In the third section, the implications of new institutional framework on the subnational debt are approached; in the fourth, the possible causes that distorted the expected path of the debt are discussed. The fifth section analyses the future perspectives for the debt in general terms and focuses some specific cases, while the sixth section discusses the problem under a federal optics. Finally, the conclusion is presented.

Key-words: Federalism; subnational debt; intergovernmental relations.

JEL Classification: H74; H77; H63.

\section{INTRODUÇÃO}

As idiossincrasias de formação do federalismo brasileiro, com a cessão de poder do Governo Central em prol dos governos subnacionais, distinguiram as relações intergovernamentais no Estado Brasileiro. Movimentos de sístole e diás-

\footnotetext{
* Do Instituto de Pesquisa Econômica Aplicada-IPEA, Av. Antonio Carlos, 51, Rio de Janeiro. Emails: mora@ipea.gov.br e fgiambia@ipea.gov.br. Os autores agradecem a Renato Villela, José Roberto Afonso e Marcelo Piancastelli pelo apoio e seus valiosos comentários, isentando-os de eventuais erros remanescentes. Desnecessário dizer que as opiniões aqui expressas são de única e exclusiva responsabilidade dos autores. Submetido: fevereiro 2006; aceito: julho 2006.
} 
tole, características do Federalismo brasileiro enfatizadas por Simonsen (1995), decorreram de um quadro marcado pela:

- fragilidade institucional;

- tentativa de minimizar os conflitos e acomodar interesses divergentes por meio das relações intergovernamentais, com soluções que freqüentemente contornavam o arcabouço legal.

A articulação entre os entes distintos se deu ao longo do tempo por meio de processos de descentralização e centralização, em consonância com o cenário político vigente. A natureza das relações intergovernamentais refletia o embate entre a autonomia dos governos subnacionais e a soberania da União, embate natural em regimes federativos, mas reforçado, no caso brasileiro, pelos fluidos referenciais institucionais. Muitas vezes a prática contradizia as regras estabelecidas, que buscavam conferir tratamento similar a entes altamente desiguais, seja politicamente, seja em termos econômicos. As peculiaridades da federação brasileira levaram a que esses conflitos se exacerbassem no processo de endividamento. ${ }^{1}$

A falta de limites, a despeito de um notável aparato regulador, já observada em Rezende (1982), caracterizou a evolução do endividamento subnacional até recentemente. A fragilidade do arcabouço institucional levou a que o Estado brasileiro se defrontasse, na década de 90, com desequilíbrios fiscais e patrimoniais no âmbito dos governos subnacionais. A impossibilidade de superação desses desajustes estritamente através da via fiscal levou à renegociação da dívida em duas diferentes circunstâncias (1993 e 1997). A primeira, restrita aos compromissos financeiros junto à União, não impediu a trajetória explosiva após 1994 (em decorrência de a dívida remanescente ser constituída de títulos indexados a Selic, negociados com deságios significativos). Quando a União propôs um abrangente refinanciamento, ${ }^{2}$ a dívida estadual, em 1996, superava os $16 \%$ do $\mathrm{PIB}^{3}$ e era um problema comum a praticamente todas unidades da federação.

Subseqüentemente, em 2000, aprovou-se com o apoio federal a Lei de Responsabilidade Fiscal (LRF). A LRF teve como pano de fundo, no âmbito externo, o Manual de Boas Práticas Fiscais publicado pelo Fundo Monetário Internacional (FMI), e as experiências de países como a Nova Zelândia; e, no plano

\footnotetext{
${ }^{1}$ A definição abrangente de Afonso (1992) considera como relações intergovernamentais, além das transferências legais e constitucionais e das transferências voluntárias, o endividamento subnacional. Uma discussão detalhada quanto à pertinência de se considerar o endividamento subnacional como relação intergovernamental é desenvolvida por Mora (2002).

${ }^{2}$ As dívidas previamente renegociadas e os precatórios foram praticamente as únicas categorias que não participaram da renegociação.

${ }^{3}$ Há indícios de que esse valor estava subestimado, ainda que fosse bem superior à dívida líquida dos governos estaduais e municipais, posto que, quando se inicia o processo de renegociação da dívida em 1996, não havia uma consolidação das dívidas subnacionais. Computada pelo Banco Central em dezembro de 1996, a dívida líquida regional (conceito em que se desconta as disponibilidades financeiras), era de $11,5 \%$ do PIB e, nos anos subseqüentes, superou os $18 \%$ do PIB.
} 
interno, representou uma tentativa de robustecer os princípios de austeridade fiscal implícitos no Programa de Reestruturação Fiscal e Financeira dos Estados.

Nos últimos anos, a trajetória da dívida fora dos padrões esperados pelas simulações, a despeito do esforço empreendido pelos governos subnacionais, levou à retomada da discussão sobre limites ao endividamento e regras institucionais. Nessa direção, há pleitos por parte de governadores e de prefeitos no sentido de rever os contratos de refinanciamento.

Este artigo, subdividido em sete seções, pretende apresentar argumentos no sentido de contestar a idéia de que o conjunto de regras vigentes para lidar com a dívida estadual deva ser substancialmente modificado. A primeira seção consistirá de uma introdução sucinta, em que o objeto em discussão é delineado em linhas gerais. A segunda tratará do aparato institucional criado para buscar o equilíbrio fiscal intertemporal no âmbito federativo. Mais especificamente serão apresentados o Programa de Reestruturação Fiscal e Financeira Estadual e a LRF. Na terceira seção, serão abordadas as implicações do novo aparato institucional sobre o endividamento subnacional; na quarta, serão debatidas as possíveis causas que distorceram a trajetória esperada da dívida. A quinta seção analisará as perspectivas futuras para a evolução do endividamento, enquanto a sexta discute o problema sob uma óptica federativa. Por fim, à guisa de considerações finais, serão expostas as principais conclusões auferidas e algumas condições necessárias para evitar a recorrência da crise.

\section{A CRIAÇÃO DE UM NOVO APARATO INSTITUCIONAL: O PROGRAMA DE REESTRUTURAÇÃO FISCAL E FINANCEIRA E A LEI DE RESPONSABILIDADE FISCAL}

Nesta seção, o aparato institucional constituído para lidar com o desequilíbrio fiscal e financeiro estadual será abordado. Tradicionalmente no Brasil, ocorreram transferências de desequilíbrios patrimoniais e fiscais no âmbito dos governos subnacionais para a União. A reestruturação da dívida subnacional inicia-se, em 1989, com a Lei 7.977, que trata especificamente dos avisos MF30 e sucedâneos. Em 1993, a Lei 8.727 permitiu a renegociaçãou a dívida de estados e municípios com a União e instituições federais, frustrando, contudo, as expectativas dos governadores e prefeitos, que pleiteavam um abrangente reescalonamento. Parte significativa da dívida subnacional permanecia em poder da iniciativa privada, sendo essa parcela a principal responsável pela trajetória explosiva do endividamento observada após 1994.

A situação fiscal e financeira dos estados caminhou rapidamente para a insolvência. ${ }^{4}$ Conforme gradualmente se delineia em 1996, a dívida atingia tal pa-

\footnotetext{
${ }^{4}$ Propulsionada em decorrência de reajustes salariais concedidos pelos governadores recém-empossados, dos contratos com empreiteiros (que embutiam uma expectativa de inflação elevada) e dos deságios pagos pelos estados para rolarem sua dívida.
} 
tamar (16,6\% do PIB) que impossibilitava soluções no âmago da administração estadual e ameaçava a estabilidade macroeconômica, exigindo uma saída negociada no âmbito da federação. Em resposta ao pleito dos governadores, a União propôs um Programa de Reestruturação Fiscal e Financeira.

O Programa de Reestruturação Fiscal e Financeira, parametrizado pela Lei 9.496/97, induziu as unidades da federação a implementarem uma reforma abrangente do Estado, em consonância com a esfera federal. O Programa foi estabelecido sobre três grandes eixos, a saber: ajuste fiscal (para viabilizar o pagamento das prestações associadas ao refinanciamento), venda de ativos estaduais (particularmente a desestatização de concessionárias estaduais de distribuição de energia elétrica) e privatização/liquidação dos bancos estaduais. Em contrapartida, os governos estaduais obtiveram o refinanciamento das suas dívidas. Somente os estados de Minas Gerais, Alagoas e Pará arcaram com taxas de juros de 7,5\% a.a., enquanto todos as demais unidades da federação tiveram sua dívida renegociada no âmbito da Lei $9.496 / 97$ indexada a uma taxa de juros de $6 \%$ a.a.

Em linhas gerais, o refinanciamento previa o pagamento de até $20 \%$ à vista, taxas de juros de $6 \%$ a $9 \%$ ao ano, cálculo das prestações baseado na Tabela Price, comprometimento de receita de $11,5 \%$ a $15 \%$ da Receita Corrente Líquida (ainda que tenham predominado os $13 \%$ ). Se o estado não dispusesse de ativos suficientes para a quitação dos $20 \%$, incidiriam sobre a dívida renegociada juros de $7,5 \%$ a.a. (pagamento de $10 \%$ ) a $9 \%$ (sem desembolso à vista).

A preocupação da União de assegurar o ajustamento fiscal das unidades da federação e de evitar a ocorrência de novos desajustes futuros suscitados pela utilização de bancos estaduais e das concessionárias de energia elétrica e pela realização de operações de crédito. decorria do receio de inviabilizar o pagamento das prestações do refinanciamento. Desse modo, buscava-se evitar que a restrição orçamentária imposta às unidades da federação fosse flexibilizada e resguardar, assim, a capacidade de pagamento. A absorção de uma dívida superior a $13 \%$ do PIB (dívida subnacional renegociável) implicou um ônus significativo para a União e tornou concretas as conseqüências do arranjo federativo em vigência. O potencial de desgaste decorrente das relações intergovernamentais e suas implicações sobre a estabilidade macroeconômica estavam explicitados.

O sucesso do Programa de Reestruturação Fiscal e Financeira dependia da capacidade de efetiva revisão das relações federativas e de imposição de limites aos governos estaduais. Era necessário inverter o papel desempenhado pelos governos subnacionais, forçando-os a gerar superávit primário em níveis condizentes com o pagamento das prestações do refinanciamento junto à União e contribuir para o esforço fiscal do setor público consolidado. A geração compulsória desses superávits primários é garantida legalmente por dispositivo constitucional, que permite à União, e somente a ela, não só reter as transferências constitucionais a estados inadimplentes, como acessar as contas recolhedoras dos tributos próprios. ${ }^{5}$

${ }^{5}$ Artigo 160, parágrafo único, Constituição de 1988. 
Vislumbrava-se, portanto, a implementação de um abrangente ajuste fiscal para obter um resultado primário condizente com o acordado nos contratos de refinanciamento. Como nessa época a receita líquida real beirava os $7 \%$ do PIB, os $13 \%$ da RLR indicavam no médio prazo uma contribuição dos governos estaduais para o esforço fiscal do setor público consolidado na ordem de 1,0\% do PIB.

Se a privatização de empresas estatais e bancos era um procedimento once for all, os desembolsos mensais de estados exigiam a prestação de contas com o governo central e deveriam reduzir gradualmente o passivo financeiro subnacional (desde que a concepção dos contratos fosse adequada).

Com a intenção de averiguar se houve falhas na concepção dos contratos e levando em consideração parâmetros mais freqüentemente observados no Quadro 1 , simula-se a trajetória da dívida, tecendo diferentes cenários macroeconômicos e supondo o pagamento das prestações do refinanciamento pelos entes da federação.

Em decorrência da participação da dívida renegociada sob a égide da Lei 9.496/97 no passivo estadual, das similaridades nas condições de reescalonamento da Lei $8.727 / 93$ e da Lei $9.496 / 97$ e dos critérios de amortização da dívida previstos pela Lei 9.496/97 (incluindo no comprometimento os serviços das demais dívidas renegociadas, assim como os compromissos com o exterior), ${ }^{6}$ optou-se por avaliar a concepção dos contratos aplicando os critérios estabelecidos pela Lei $9496 / 97$ ao estoque total de dívida e, assim, simular a trajetória do endividamento nos 30 anos subseqüente à assinatura dos contratos de refinanciamento.

Cabe lembrar que a prestação X que os Estados pagam de fato é dada por $\mathrm{X}=\min (\mathrm{P}, \mathrm{x}$. Receita); condicionado à existência de saldo acumulado decorrente de (P -x.Receita);(1) onde $\mathrm{P}$ = prestação da Tabela Price e x é o limite de comprometimento - em geral, $13 \%$.

Esse processo de ajustamento está descrito no Gráfico 1. Portanto, se P é maior que o limite de comprometimento, o que os estados pagam está sujeito a esse limite. A diferença entre $\mathrm{P}$ e o saldo vai se acumulando em uma conta separada, reajustada segundo os mesmos critérios do principal. O pagamento da prestação prevista pela Tabela Price está condicionado à quitação do saldo acumulado em decorrência da diferença entre as prestações previstas pela Price e a receita máxima prevista em contrato (ponto B do Gráfico 1). Aqui cabe ressaltar que, segundo a lógica da concepção da Price, nas prestações iniciais preponderam o pagamento de juros. Gradualmente, a relação entre juros e amortização se inverte.

\footnotetext{
${ }^{6}$ Havia uma regra nos contratos de refinanciamento, priorizando, nessa ordem, os compromissos com o exterior, seguidos, respectivamente, pelos desembolsos relativos à Lei 7.977/89 e à Lei 8.727/93 e, por fim, pelos pagamentos referentes à Lei 9.496/97.
} 
Gráfico 1: A lógica dos contratos de refinanciamento:

comprometimento RLR x prestação Price

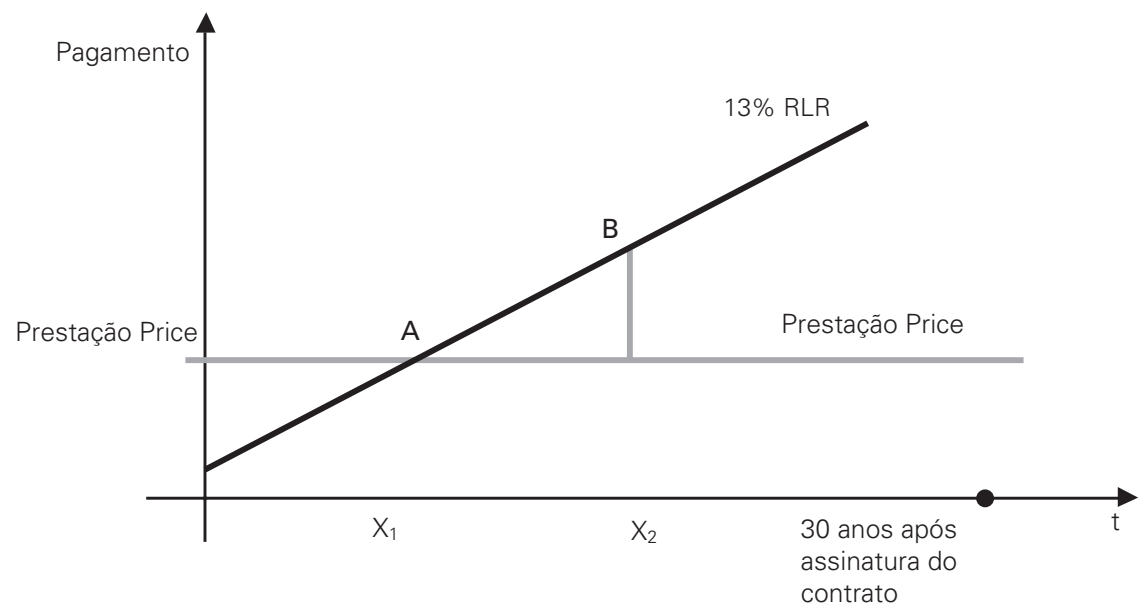

A Tabela 1 mostra que: a) para uma dívida igual ou maior a 2, o limite de $13 \%$ já é ultrapassado; e b) a prestação calculada pela Tabela Price sobe muito se a taxa de juros real é de $9 \%$ ao invés de $6 \%$.

\section{Tabela 1: Relação prestação da tabela Price/receita inicial}

Para dados valores da taxa de juros real anual (i) e da relação Dívida/Receita inicial (d0), com um prazo de 30 anos

\begin{tabular}{rrrrr}
\hline & $d 0=2,0$ & $d 0=2,5$ & $d 0=3,0$ & $d 0=3,5$ \\
\hline$i=6 \%$ & 14,50 & 18,20 & 21,80 & 25,40 \\
\hline$i=9 \%$ & 19,50 & 24,30 & 29,20 & 34,10 \\
\hline
\end{tabular}

É exatamente a distância existente entre os valores que resultam da Tabela 1 - para valores altos de $\mathrm{d}$ - e o teto de comprometimento, que explica por que, durante muitos anos, estados, mesmo pagando valores reais crescentes em função do aumento da receita à qual se aplica o limite, estariam ainda abaixo da prestação devida P calculada pela Tabela Price — que é uma constante. Nesse caso, o limite de comprometimento e a prestação $\mathrm{P}$ da Tabela Price deveriam se igualar em algum ponto, em alguns anos, para os casos de endividamento inicial elevado, conforme apontado pela Tabela 2 e pelo Gráfico 1. 
Tabela 2: Comprometimento de receita e prestação da tabela Price

Primeiro ano de pagamento da prestaçao com base na tabela Price ${ }^{1}$

\begin{tabular}{|c|c|c|c|c|c|c|c|c|}
\hline & \multicolumn{8}{|c|}{ Taxa de juros real } \\
\hline & \multicolumn{4}{|c|}{$6 \%$} & \multicolumn{4}{|c|}{$9 \%$} \\
\hline \multirow{3}{*}{ 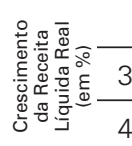 } & $d=2,0$ & $d=2,5$ & $d=3,0$ & $d=3,5$ & $d=2,0$ & $d=2,5$ & $d=3,0$ & $d=3,5$ \\
\hline & 7 anos & 24 anos & & & & & & \\
\hline & 3 anos & 17 anos & 27 anos & - & 22 anos & & & \\
\hline
\end{tabular}

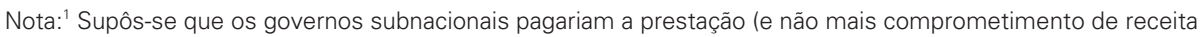
previsto em contrato) somente quando não mais restasse resíduo decorrente da diferença entre a prestação prevista pela tabela Price e o comprometimento de receita.

Levando em consideração o arcabouço conceitual que pauta a construção da Tabela Price e as particularidades do refinanciamento baseadas no conteúdo da Lei 9496/97, a evolução de dívida foi simulada. As receitas estaduais no agregado foram supostas estáveis vis-à-vis ao PIB.

Com base nos parâmetros dos contratos de refinanciamento, a Tabela 3 mostra os resultados da simulação da trajetória do endividamento, considerando um comprometimento de receita de $13 \%$ e diferentes taxas de juros $(6 \%, 7,5 \%$ e $9 \%)$ e diferentes taxas de crescimento da receita líquida real $(2 \%, 3 \%$ e $4 \%$ ao ano; ainda que os $2 \%$ sejam considerados, em termos de longo prazo, uma taxa muito baixa).

Tabela 3: Síntese das simulações

Relação dívida/receita no final de 30 anos

\begin{tabular}{|c|c|c|c|c|c|c|c|c|c|c|c|c|}
\hline \multicolumn{13}{|c|}{ Taxa de juros real (\%)) } \\
\hline & \multicolumn{4}{|c|}{$6,0 \%$} & \multicolumn{4}{|c|}{$7,5 \%$} & \multicolumn{4}{|c|}{$9,0 \%$} \\
\hline \multirow{4}{*}{ 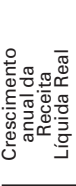 } & $d_{0}=2,0$ & $d_{0}=2,5$ & $d_{0}=3,0$ & $d_{0}=3,5$ & $d_{0}=2,0$ & $d_{0}=2,5$ & $d_{0}=3,0$ & $d_{0}=3,5$ & $d_{0}=2,0$ & $d_{0}=2,5$ & $d_{0}=3,0$ & $d_{0}=3,5$ \\
\hline & 0,00 & 0,17 & 1,61 & 3,79 & 0,00 & 1,56 & 5,06 & 7,49 & 0,78 & 5,79 & 9,69 & 13,38 \\
\hline & 0,00 & 0,00 & 0,31 & 1,28 & 0,00 & 0,23 & 1,54 & 3,72 & 0,00 & 1,37 & 4,40 & 8,97 \\
\hline & 0,00 & 0,00 & 0,00 & 0,29 & 0,00 & 0,00 & 0,37 & 1,29 & 0,00 & 0,24 & 1,44 & 3,30 \\
\hline
\end{tabular}

Obs.: Os números em negrito correspondem aos casos em que a relação dívida/receita no final de 30 anos é maior que a relação inicial.

Da análise das tabelas se extrai que não houve falha de concepção na construção das simulações de trajetória de endividamento estadual para taxas de juros de $6 \%$. Em termos gerais, se preponderassem taxas estáveis de crescimento da economia e do índice de preços, a receita estadual acompanhasse o PIB nacional, prevalecessem taxas de juros de $6 \%$ a.a. e as prestações fossem pagas, a tendência seria de redução gradual e contínua da dívida. Vale ressaltar que a manutenção dos parâmetros dentro dos limites estabelecidos era condição sine qua non para que o cronograma de queda da dívida fosse respeitado. Para a taxa de 
juros de $7,5 \%$, o comprometimento de $13 \%$ não seria suficiente para relações divida/receita igual ou superiores a 2,5 se a economia apresentasse um crescimento medíocre. No caso dos juros a $9 \%$, a trajetória da dívida tende a ser divergente se a relação dívida inicial/receita for elevada e a economia não apresentar elevadas taxas de crescimento.

A LRF pode ser considerada um desdobramento do Programa de Reestruturação Fiscal e Financeira, e ainda que tenham sido sobrepostos, ambos, são em linhas gerais complementares. ${ }^{7}$ Promulgada em 2000, a LRF ensejava construir um aparato institucional compatível com o equilíbrio fiscal intertemporal através, entre outras medidas, da introdução de novos parâmetros para as finanças públicas subnacionais e para as relações federativas.

$\mathrm{O}$ arcabouço legal, apoiado em uma Lei Complementar, estabelecia regras e limites para as três esferas de poder, face à constatação de que esses limites não eram intrínsecos (particularmente no âmbito estadual e municipal). Conforme mencionado por Giambiagi e Rigolon (1999):

“(...) Na verdade, a estabilização macroeconômica não é percebida como um objetivo de política estadual e os custos de esperar, sob a óptica dos governos e dos grupos locais, são muito baixos. Nesse caso, é possível que nenhum grupo socioeconômico do próprio estado se disponha a suportar o ônus do ajuste e o governo central seja forçado a intervir. A recente renegociação das dívidas estaduais pode ser interpretada como uma tentativa do governo central de induzir a um ajuste governos estaduais, que, na prática, não têm qualquer incentivo para fazê-lo voluntariamente. (...)" (Giambiagi e Rigolon, 1999:25)

Para assegurar o equilíbrio fiscal intertemporal, foram instituídos alguns mecanismos diretos e indiretos de controle ao endividamento. A definição de tetos para a despesa com os poderes legislativo e judiciário, o estabelecimento de limites para gastos com funcionalismo e a criação de regras específicas para despesas obrigatórias de caráter continuado visavam evitar novos déficits orçamentários e, conseqüentemente, o descontrole fiscal. Em última instância, tinha-se por finalidade impedir a recorrência de crises financeiras, como a observada em meados da década de 90.

Efetivamente, essas medidas surtiram efeito. O comprometimento com o equilíbrio fiscal é uma constante em praticamente todas as administrações estaduais. Ainda que haja eventuais distorções, a implementação da LRF levou a que esses desajustes fossem pontuais e não generalizados.

\footnotetext{
${ }^{7}$ A Resolução do Senado ${ }^{\circ} 40$ e a Resolução do Senado n ${ }^{\circ} 43$, ambas de 2001, atualmente regulamentam as operações de crédito e respeitam as orientações da Lei de Responsabilidade Fiscal. Contudo, os estados ainda estão sujeitos ao Programa de Reestruturação Fiscal e Financeira. Ambos dispõem de termos e conceitos diferentes, e as unidades da federação devem estar aptas a satisfazer a ambos.
} 
Adicionalmente, para evitar que novamente desequilíbrios fiscais fossem transferidos para outros níveis de governo, interditou-se a possibilidade de empréstimos ou financiamentos entre entes da federação. Designou-se ao Senado, instância responsável constitucionalmente por arbitrar conflitos federativos e, por extensão, pela regulamentação do endividamento subnacional, a definição de limites ao estoque de dívida. Esses limites deveriam satisfazer os seguintes princípios:

$\mathbb{S} 1^{\circ}$ As propostas referidas nos incisos I e II do caput e suas alterações conterão:

I - demonstração de que os limites e condições guardam coerência com as normas estabelecidas nesta Lei Complementar e com os objetivos da política fiscal;

II - estimativas do impacto da aplicação dos limites a cada uma das três esferas de governo;

III - razões de eventual proposição de limites diferenciados por esfera de governo;

IV - metodologia de apuração dos resultados primário e nominal.

Implicitamente, estipulava-se que os limites deveriam assegurar o equilíbrio fiscal intertemporal para, assim, guardar coerência com as normas estabelecidas na Lei Complementar. No artigo 30, ao remeter para a legislação ordinária a definição dos limites, a LRF estabelece também situações passíveis de revisão de limites.

$\mathbb{S} 6^{\circ}$ Sempre que alterados os fundamentos das propostas de que trata este artigo, em razão de instabilidade econômica ou alterações nas políticas monetária ou cambial, o Presidente da República poderá encaminhar ao Senado Federal ou ao Congresso Nacional solicitação de revisão dos limites.

Em resposta às demandas da Lei de Responsabilidade Fiscal, foram aprovadas, ao final de 2001, Resoluções do Senado ${ }^{\circ s} 40$ e 43, que passam a regulamentar as operações de crédito subnacionais, substituindo a Resolução do Senado $\mathrm{n}^{\circ} 78$, de 1998. As resoluções, promulgadas à reboque da LRF, estabelecem como parâmetro ao endividamento a Receita Corrente Líquida e os seguintes limites:

- Operações de Crédito no Ano - 16\% da Receita Corrente Líquida

- Serviços da Dívida - 11,5\% da Receita Corrente Líquida

- Aro's - 7\% da Receita Corrente Líquida

- Garantias - 22 a 32\% da Receita Corrente Líquida

Como limite ao endividamento, foi estabelecido que a relação dívida consolidada líquida/receita corrente líquida não deveria extrapolar a razão de 2, no caso dos estados, e 1,2 no caso dos municípios. O endividamento de alguns estados e municípios superava o considerado prudente em termos de equilíbrio intertemporal. A saída encontrada foi a estipulação de um prazo para a recondução dos limites de 15 anos, com uma redução gradual à velocidade de um quinze avos por ano. 
Já que particularidades da dívida consolidada líquida, das quais são extraídas, por definição, as disponibilidades financeiras, dificultam a construção de cenários prospectivos, realizou-se a simulação para a dívida consolidada/receita líquida real, que, por definição, é superior à relação dívida consolidada líquida/receita corrente líquida (vide Tabela 5, na seção 3). Portanto, os estados que se ajustassem pelo primeiro conceito também se ajustariam ao segundo.

\section{A EXECUÇÃO DO PROGRAMA DE REESTRUTURAÇÃO FISCAL E FINANCEIRA E SUAS IMPLICAÇÕES SOBRE A DÍVIDA SUBNACIONAL}

Os resultados obtidos com os três principais eixos do programa (a saber, privatizações, venda ou liquidação de instituições financeiras estaduais e ajustamento fiscal) permitem que o êxito da execução do Programa de Reestruturação Fiscal e Financeira seja avaliado, considerando como indicador a evolução da trajetória da dívida esperada e a efetiva.

A concepção do refinanciamento sinalizava que a trajetória da dívida deveria ser continuamente descendente na maior parte dos casos desde que os parâmetros respeitassem as condições previstas contratualmente.

Aplicou-se sobre o estoque de dívida total, os critérios dispostos pela Lei 9.496/97. ${ }^{8}$ A Tabela 4 resume os resultados esperados sete anos após a vigência dos contratos, dados diferentes estoques de dívida. Aqui vale ressaltar que os contratos assinados entre os entes da federação e a União não são de conhecimento público. Portanto, consideraram-se as condições gerais explicitadas nas Resoluções do Senado que autorizaram a negociação das operações de crédito e na Lei 9.496/97.

Tabela 4: Síntese das simulações

Relação dívida/receita no final de 7 anos

\begin{tabular}{|c|c|c|c|c|c|c|c|c|c|c|c|c|}
\hline \multicolumn{13}{|c|}{ Taxa de juros real (\%)) } \\
\hline & \multicolumn{4}{|c|}{$6,0 \%$} & \multicolumn{4}{|c|}{$7,5 \%$} & \multicolumn{4}{|c|}{$9,0 \%$} \\
\hline \multirow{4}{*}{ 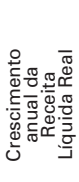 } & $d_{0}=2,0$ & $d_{0}=2,5$ & $d_{0}=3,0$ & $d_{0}=3,5$ & $d_{0}=2,0$ & $d_{0}=2,5$ & $d_{0}=3,0$ & $\mathrm{~d}_{0}=3,5$ & $d_{0}=2,0$ & $d_{0}=2,5$ & $d_{0}=3,0$ & $d_{0}=3,5$ \\
\hline & 1,57 & 2,23 & 2,89 & 3,54 & 1,79 & 2,52 & 3,24 & 3,97 & 2,03 & 2,83 & 3,63 & 4,43 \\
\hline & 1,45 & 2,05 & 2,66 & 3,28 & 1,64 & 2,32 & 2,99 & 3,67 & 1,86 & 2,61 & 3,35 & 4,10 \\
\hline & 1,36 & 1,89 & 2,46 & 3,03 & 1,49 & 2,13 & 2,76 & 3,40 & 1,71 & 2,40 & 3,10 & 3,80 \\
\hline
\end{tabular}

Segundo a Tabela 4 , se a receita crescesse a uma taxa real de $4 \%$ ao ano, com uma taxa de juros de $6 \%$ ao ano, não houvesse novas operações de crédito e ocorresse o pagamento das prestações do refinanciamento, os estados com uma

${ }^{8}$ Vide argumentos na seção 2. 
relação dívida consolidada/receita líquida real entre 3,0 e 3,5, por exemplo, teriam uma relação dívida consolidada/receita líquida real de aproximadamente entre 2,46 e 3,03 no final de 2004.

Tomando como base as simulações apresentadas na Tabela 4, será comparada a trajetória esperada do endividamento estadual com a efetivamente observada, com a intenção de avaliar as implicações do arcabouço institucional sobre a trajetória do endividamento.

A relação dívida consolidada/receita líquida real, efetivamente observada na Tabela 5 entre 2001 e 2005, não apresenta a tendência à queda conforme simulação realizada e sintetizada pela Tabela 4. A relação manteve-se, de fato, relativamente estável para os estados em termos agregados, e alguns dos mais endividados viram sua dívida crescer. Extraindo-se aqueles cuja dívida se elevou, constata-se uma tendência à queda dos demais. Os estados do Centro-Oeste contribuíram positivamente para esse movimento, facilitado pelo comprometimento de receita de $15 \%$ (adotado em decorrência do elevado estoque de dívida dessas unidades da federação). Ato contínuo, a seção seguinte discutirá possíveis causas para o comportamento da dívida.

Tabela 5: Dívida consolidada e Receita Líquida Real - Evolução recente (1998-1º Quad/05)

\begin{tabular}{lcccccc}
\hline & dez/00 & dez/01 & dez/02 & dez/03 & dez/04 & 10 0/05 \\
\hline Região Norte & 0,96 & 0,84 & 0,86 & 0,75 & 0,70 & 0,67 \\
\hline Acre & 1,29 & 1,00 & 0,90 & 0,82 & 0,76 & 0,72 \\
\hline Amazonas & 1,19 & 1,04 & 1,00 & 0,75 & 0,67 & 0,61 \\
\hline Pará & 0,77 & 0,74 & 0,82 & 0,69 & 0,69 & 0,65 \\
\hline Rondônia /2 & 1,97 & 1,62 & 1,45 & 1,35 & 1,32 & 1,30 \\
\hline Amapá & 0,21 & 0,15 & 0,22 & 0,31 & 0,28 & 0,27 \\
\hline Roraima & 0,42 & 0,39 & 0,51 & 0,46 & 0,43 & 0,55 \\
\hline Tocantins & 0,57 & 0,56 & 0,75 & 0,61 & 0,55 & 0,48 \\
\hline Região Nordeste & 1,87 & 1,78 & 1,89 & 1,59 & 1,57 & 1,45 \\
\hline Maranhão & 2,60 & 2,41 & 2,65 & 2,24 & 2,34 & 2,23 \\
\hline Piauí & 2,42 & 2,20 & 2,27 & 1,97 & 1,85 & 1,72 \\
\hline Ceará & 1,43 & 1,37 & 1,54 & 1,20 & 1,15 & 0,98 \\
\hline Rio Grande do Norte & 0,66 & 0,68 & 0,75 & 0,62 & 0,55 & 0,60 \\
\hline Paraíba & 1,93 & 1,55 & 1,60 & 1,35 & 1,38 & 1,29 \\
\hline Pernambuco & 1,64 & 1,64 & 1,65 & 1,40 & 1,31 & 1,25 \\
\hline Alagoas & 3,10 & 2,70 & 3,11 & 3,06 & 3,08 & 2,87 \\
\hline Sergipe & 1,10 & 0,97 & 0,92 & 0,80 & 0,78 & 0,75 \\
\hline Bahia & 2,25 & 2,19 & 2,29 & 1,83 & 1,84 & 1,67 \\
\hline & & & & & & \\
\hline
\end{tabular}




\begin{tabular}{lllllll}
\hline Região Sudeste & 2,94 & 2,83 & 3,19 & 2,95 & 3,07 & 2,98 \\
\hline Minas Gerais & 3,41 & 3,34 & 3,57 & 3,05 & 3,44 & 3,20 \\
\hline Espiríto Santo & 0,90 & 0,82 & 1,23 & 1,18 & 0,96 & 0,90 \\
\hline Rio de Janeiro & 3,82 & 3,63 & 3,52 & 3,08 & 2,95 & 2,89 \\
\hline São Paulo & 2,72 & 2,63 & 3,11 & 3,02 & 3,19 & 3,14 \\
\hline Região Sul & 2,78 & 2,47 & 2,93 & 2,63 & 2,66 & 2,64 \\
\hline Paraná & 1,62 & 1,64 & 2,13 & 1,86 & 1,94 & 1,87 \\
\hline Santa Catarina /2 & 2,57 & 2,23 & 2,68 & 2,30 & 2,19 & 2,14 \\
\hline Rio Grande do Sul & 3,95 & 3,31 & 3,74 & 3,45 & 3,51 & 3,57 \\
\hline Região Centro-Oeste & 1,95 & 1,88 & 1,93 & 2,02 & 1,89 & 1,84 \\
\hline Mato Grosso & 2,97 & 3,26 & 2,96 & 2,46 & 1,96 & 1,82 \\
\hline Mato Grosso do Sul & 4,44 & 3,98 & 4,14 & 3,52 & 2,96 & 2,88 \\
\hline Goiás & 4,04 & 3,77 & 3,83 & 3,44 & 3,19 & 3,20 \\
\hline Distrito Federal & 0,27 & 0,24 & 0,29 & 0,38 & 0,37 & 0,37 \\
\hline Total & 2,45 & 2,32 & 2,57 & 2,36 & 2,40 & 2,32 \\
\hline Total (sem São Paulo) & 2,63 & 2,35 & 2,20 & 2,36 & 2,12 & 2,02 \\
\hline Total (sem SP, RS e AL) & 2,52 & 2,18 & 2,09 & 2,22 & 1,99 & 1,87 \\
\hline Fontes Secren
\end{tabular}

Fontes: Secretaria do Tesouro Nacional e Banco Central.

Notas: 2000 a 2004: Indicadores Fiscais (site STN); ${ }^{2}$ A coluna de 2004 refere-se ao $2^{\circ}$ quadrimestre do ano.

\section{O IMPACTO DE ALGUMAS VARIÁVEIS INDEPENDENTES SOBRE O MODELO}

No plano teórico, a relação dívida/receita (d) é função basicamente de três parâmetros, a saber: taxa de juros (i), relação inicial dívida/receita $\left(\mathrm{d}_{\mathrm{O}}\right)$ e proporção entre prestação a ser desembolsada e receita $(\mathrm{p})$. Donde:

$\mathrm{d}=\mathrm{f}\left(\mathrm{i}, \mathrm{d}_{\mathrm{o}}, \mathrm{p}\right)$

Esses parâmetros seriam afetados pela evolução do IGP-DI (que repercutiria sobre os juros) e pelo desempenho da receita. As receitas estaduais cumpririam um papel fundamental para a amortização do estoque de dívida no modelo desenhado pelos formuladores do Programa de Reestruturação Fiscal e Financeira. Conforme apresentado no Gráfico 1, a elevação das receitas tenderia a aproximar e posteriormente superar a prestação prevista pela Price, compatibilizando a lógica do comprometimento de receita com estoques elevados de dívida. Adicionalmente, segundo os contratos, enquanto houvesse resíduo, os estados pagariam o percentual de comprometimento de receita acordado.

No campo concreto, essas variáveis, associadas à execução do Programa de Reestruturação Fiscal e Financeira, poderiam justificar a frustração das expectativas de queda da relação dívida/receita. 
Vamos discutir o impacto dessas variáveis independentes sobre os resultados do modelo para ter elementos concretos para discutir os pleitos no sentido de renegociar a dívida subnacional e/ou de redefinir os parâmetros do refinanciamento.

O pagamento das prestações requereu um aumento do superávit primário de estados. Se o desembolso dos governos estaduais seria determinante para a redução do estoque do passivo subnacional, este também contribuiria para o esforço fiscal do setor público consolidado.

Como os estados em consonância com o Programa de Reestruturação Fiscal e Financeira pagaram as prestações do refinanciamento da dívida (ou seja, no agregado, grosso modo, $13 \%$ da RLR $)^{9}$ e com o gradual esgotamento dos recursos provenientes do processo de desestatização, as necessidades de financiamento dos governos subnacionais tendem a se manter em $1 \%$ do PIB.

A implementação do Programa de Reestruturação Fiscal e Financeira requereu dos estados iniciativas para reverter a situação deficitária, criando as condições necessárias para o pagamento das prestações do refinanciamento da dívida estadual. O monitoramento das finanças subnacionais pela STN levou a um superávit primário crescente calcado no aumento das receitas estaduais. A evolução da Receita Líquida Real após 1999 se eleva até alcançar, em 2004, R\$ 143 bilhões (Tabela 6).

Tabela 6: Comparação da Receita

Líquida Real e do PIB - 1999 X 2004

Em \% do PIB

\begin{tabular}{lrrrc}
\hline Variável & 1999 & 2004 & Var \% & Var. média anual (em \%) \\
\hline Receita Líquida Real (em \% do PIB) & $8,09 \%$ & $8,45 \%$ & 4,35 & 0,87 \\
\hline
\end{tabular}

Fonte: STN.

A Tabela 7 explicita que o ajuste fiscal nos estados, do ponto de vista agregado, ocorreu preponderantemente por meio de um aumento de receita disponível do PIB, entre 1997 e 2003, da ordem de 1,5 ponto percentual do PIB em menos de 10 anos, equivalendo, grosso modo, à reversão do déficit primário de estadual de 0,74\% do PIB observada em 1997, para o superávit primário dos governos estaduais de $0,77 \%$ do PIB em 2003.

${ }^{9}$ De acordo com a Secretaria do Tesouro Nacional, as unidades da federação estão adimplentes. 
Tabela 7: Carga tributária

Conceito contas nacionais 1997-2003

Em \% do PIB

\begin{tabular}{l|c|c|c|c}
\hline & & \multicolumn{3}{|c}{ Participação receita disponível } \\
\hline Ano & $\begin{array}{c}\text { Carga } \\
\text { tributária }\end{array}$ & União & Estados & Municípios \\
\hline 1997 & 28,58 & 15,13 & 8,20 & 5,25 \\
\hline 1998 & 29,33 & 15,16 & 8,32 & 5,85 \\
\hline 1999 & 31,07 & 16,52 & 8,40 & 6,15 \\
\hline 2000 & 31,61 & 16,18 & 9,31 & 6,12 \\
\hline 2001 & 33,36 & 16,85 & 9,86 & 6,65 \\
\hline 2002 & 34,88 & 18,12 & 10,50 & 6,26 \\
\hline 2003 & 34,01 & 17,74 & 9,70 & 6,57 \\
\hline
\end{tabular}

Fonte: IBGE.

O comportamento dos principais componentes da receita estadual, seja ela própria ou oriunda de transferências, reforça essa tese e indica que, em 2004, a tendência seria também de crescimento. A arrecadação do ICMS, por exemplo, cresceu, entre 1998 e 2005 , de $6,7 \%$ para $8 \%$ do PIB.

Reproduziram-se, assim, os métodos também observados na esfera federal, quais sejam, de canalizar esforços para aumentar a arrecadação, por serem menos custosos em termos políticos no curto prazo. Essa estratégia contribuiu para o aumento da carga tributária observada no período. Além disso, atenua-se a pressão que o Programa de Reestruturação Fiscal e Financeira implicava em termos de pacto federativo decorrente das conseqüências intrínsecas a um processo de ajustamento fiscal. Entretanto, a frustração das expectativas quanto à performance da economia (entre 1998 e 2004, o PIB cresceu, em média, somente $2 \%$ ao ano) reduziu a capacidade de crescimento das receitas subnacionais. $\mathrm{O}$ crescimento das receitas acima do PIB reduziu, em alguma medida, o impacto negativo que a frustração da expectativa de crescimento do produto causaria sobre o modelo.

A indexação da dívida pelo IGP-DI reduziu a importância dos ganhos reais de receita observados quando deflacionada por outros índices, arrefecendo a capacidade de redução gradual da dívida. Em decorrência de as desvalorizações cambiais em 1999 e 2002 terem repercutido mais intensamente sobre o IGP-DI do que sobre os demais indexadores de preços ao consumidor, houve um descolamento entre os índices. A diferença acumulada entre o IGP-DI e o IPCA, no acumulado entre 1998 e 2005, por exemplo, atingiu 35\% (Tabela 8). Assim, dependendo do índice de deflação utilizado, os resultados podem ser bem diferenciados e indicar diferentes tendências. 
Número índice base, $1998=100$

\begin{tabular}{lccc}
\hline & IGP-DI (a) & IPCA (b) & (a)/(b)*100 \\
\hline 1998 & 100,0 & 100,0 & 100,0 \\
\hline 1999 & 120,0 & 108,9 & 110,2 \\
\hline 2000 & 131,8 & 115,4 & 114,2 \\
\hline 2001 & 145,5 & 124,3 & 117,1 \\
\hline 2002 & 183,9 & 139,9 & 131,5 \\
\hline 2003 & 198,0 & 152,9 & 129,5 \\
\hline 2004 & 222,0 & 164,5 & 135,0 \\
\hline
\end{tabular}

Fontes: IBGE e FGV.

Ainda que a receita estadual tenha apresentado um bom desempenho, seja quando cotejada com o PIB, seja deflacionada pelo IPCA, sua performance foi medíocre se considerarmos o IGP-DI como indexador. Assim, a relação prestação/receita líquida real foi deslocada, já que a prestação foi reajustada pelo IGPDI e não necessariamente a receita líquida real conseguiu acompanhar seu ritmo.

A própria lógica do sistema Price potencializou os efeitos do IGP-DI sobre o estoque de dívidas. Supondo prestações constantes, desembolsa-se uma parcela maior de juros no início do refinanciamento e, gradualmente, com a redução dos juros, a amortização torna-se mais expressiva. Conforme mostram as Tabela $1 \mathrm{e}$ 2 , as prestações muitas vezes sequer eram suficientes para o pagamento da totalidade dos juros. Como conseqüência, o endividamento subnacional cresceu significativamente em 2002, voltando a traçar uma trajetória descendente somente no ano posterior. O efeito do IGP-DI sobre as dívidas foi o responsável pela manutenção dos patamares de relação dívida/receita, sem que se tenha observado a queda esperada.

Pode-se conceber o efeito do descolamento do IGP-DI e do IPCA como um propulsor das taxas de juros, levando a uma elevação da taxa de juros efetiva paga pelos estados. A diferença entre a taxa de juros prevista e aquela efetiva (decorrente do impacto do descolamento entre os índices sobre o estoque) seria, no acumulado entre 1998 e 2004, de 35\%.

A repercussão se dá com uma defasagem no tempo. Se em cinco anos o IGPDI implica um acréscimo na taxas de juros de 6,2\% a.a., gradualmente o efeito tende a se diluir. Assim, em 10 anos ainda será percebido um incremento de 3\% a.a. e, ao final de 30 anos, $1 \%$ a.a. Essa situação está descrita na Tabela 9.

Tabela 9: Efeito sobre a taxa de juros real média de uma superindexação do indexador de $35 \%$

\begin{tabular}{lc}
\hline Tempo & $\%$ aa \\
\hline em cinco anos & 6,2 \\
\hline em 10 anos & 3 \\
\hline em 30 anos & 1 \\
\hline
\end{tabular}


Conclui-se que o impacto do IGP-DI sobre a relação dívida/receita afetou a trajetória de queda, mas tende a ser gradualmente absorvido. O comportamento da dívida em 2005 reforça essa hipótese. Adicionalmente, com as sucessivas deflações do IGP-DI, o estoque de dívida, assim como as receitas, serão afetados positivamente, atenuando os efeitos do descolamento entre o IGP-DI e o IPCA.

\section{PERSPECTIVAS}

Em termos agregados, ainda que a dívida não tenha decrescido na velocidade esperada, a política de ajuste fiscal contínua e persistente gerou excelentes resultados. Os estados contribuíram com cerca de 0,9\% do PIB em 2006 para o esforço fiscal do setor público consolidado, e a relação dívida consolidada/receita líquida real no agregado Brasil vem decrescendo desde 2002. Se nada de excepcional ocorrer, a tendência é de queda contínua da dívida. Assim, a condição de equilíbrio intertemporal fiscal de endividamento de duas vezes a receita corrente líquida é respeitada em termos globais, ainda que haja alguns desajustes específicos (Alagoas, Rio de Janeiro, São Paulo, Rio Grande do Sul, Mato Grosso do Sul e Goiás).

Em decorrência do comportamento das variáveis independentes, tivemos o movimento de deslocamento da trajetória da dívida, mas esta, na grande maioria dos casos, continua compatível com o equilíbrio fiscal intertemporal.

Refeitos os cálculos, reconstruiu-se a trajetória da relação dívida consolidada e receita líquida real para um prazo de 360 meses, considerando como referência a relação dívida/receita observada em dezembro de 2004 e supondo o início do refinanciamento em janeiro de 1998 (e, portanto, faltando 23 anos para completar o prazo). Buscou-se, assim, incorporar o efeito do IGP-DI e avaliar a perspectiva atual de evolução da dívida (Tabela 10).

Ao final do contrato, ou seja, findo o prazo de 30 anos, taxas de juros de $6 \%$ são, em linhas gerais, compatíveis com relações dívida/receita de até 3,0 e crescimento de $3 \%$, considerando a possibilidade de pagamento de resíduo. Relações dívida/receita de 3,5 ou mais elevadas exigiriam um crescimento médio anual da receita líquida real de aproximadamente $4 \%$ (ou mais) para tornar a dívida compatível com o resíduo. Combinações mais desfavoráveis (como taxas de juros mais elevadas com a mesma relação dívida/receita ou relações entre dívidas e receitas mais elevadas, com taxas de juros de $6 \%$ ) apresentam grande chance de assumir uma trajetória explosiva. 
Tabela 10: Síntese das simulações

Relação dívida/receita no final de 23 anos

\begin{tabular}{|c|c|c|c|c|c|c|c|c|c|c|c|c|}
\hline & \multicolumn{12}{|c|}{ Taxa de Juros Real (\%) } \\
\hline & \multicolumn{4}{|c|}{$6,0 \%$} & \multicolumn{4}{|c|}{$7,5 \%$} & \multicolumn{4}{|c|}{$9,0 \%$} \\
\hline & $d=2,0$ & $d=2,5$ & $d=3,0$ & $d=3,5$ & $d=2,0$ & $d=2,5$ & $d=3,0$ & $d=3,5$ & $d=2,0$ & $d=2,5$ & $d=3,0$ & $d=3,5$ \\
\hline 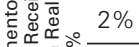 & 0,00 & 0,64 & 1,97 & 3,69 & 0,19 & 1,50 & 4,03 & 5,93 & 0,68 & 2,97 & 6,79 & 9,10 \\
\hline 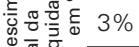 & 0,00 & 0,11 & 0,80 & 1,73 & 0,00 & 0,52 & 1,57 & 3,09 & 0,09 & 1,08 & 2,72 & 5,25 \\
\hline U $\underset{\pi}{\vec{c}}$ & 0,00 & 0,00 & 0,26 & 0,82 & 0,00 & 0,06 & 0,68 & 1,49 & 0,00 & 0,38 & 1,24 & 2,41 \\
\hline
\end{tabular}

Esses cálculos sugerem que a dívida da maior parte das UFs deverá chegar ao final do prazo estipulado em contrato, com a dívida quitada ou, ao menos, convergente, ainda que a trajetória do endividamento, tenha se deslocado. Alguns estados, contudo, estão em uma situação delicada (ver Tabelas 4 e 13).

Assim, o impacto sobre os estados dependerá do estoque de dívida atual, do efetivo pagamento realizado pelos estados, da taxa de juros estipulada contratualmente e da combinação entre essas variáveis.

Somente os estados de Alagoas, Goiás, Mato Grosso do Sul, Minas Gerais, Rio Grande do Sul e São Paulo desrespeitavam os limites ao endividamento estipulados pela LRF em abril de 2005 e devem se ajustar para atingi-los em 2016.

A Tabela 11 resulta de um esforço para avaliar a evolução da dívida estadual dos estados com relação dívida/receita mais elevada e a perspectiva de quitá-la em um prazo de 30 anos. Considerou-se o passivo estadual em abril de 2005, a data de assinatura do contrato e as condições estipuladas em cada contrato. Com base nessa tabela, pode-se afirmar que, caso não ocorram eventos extraordinários que desloquem a trajetória da dívida, se houver um crescimento anual de $4 \%$, a dívida da grande maioria dos estados estaria equacionada quando não em 30, em 40 anos (considerando a possibilidade de pagamento do resíduo).

Tabela 11: Síntese das simulações

Relação dívida/receita no final de 30 anos $^{1}$

\begin{tabular}{l|c|c|c|c|c|c|c|c}
\hline Estado & & $\mathrm{MG}^{2}$ & $\mathrm{RJ}$ & $\mathrm{SP}$ & $\mathrm{RS}$ & $\mathrm{MS}$ & $\mathrm{GO}$ & $\mathrm{AL}$ \\
\hline $\begin{array}{l}\text { Relação dívida } \\
\text { receita em } 1^{\circ} \mathrm{Q} / 05\end{array}$ & & 3,20 & 2,89 & 3,14 & 3,57 & 2,88 & 3,20 & 2,87 \\
\hline $\begin{array}{l}\text { Crescimento anual da } \\
\text { Receita Líquida Real em \% }\end{array}$ & $3 \%$ & 1,69 & 0,53 & 1,10 & 1,88 & 0,13 & 0,54 & 0,10 \\
\hline & $4 \%$ & 0,76 & 0,05 & 0,47 & 0,91 & 0,00 & 0,08 & 0,00 \\
\hline
\end{tabular}

Fonte: Elaboração própria.

Notas: " Esta tabela foi construída considerando a data de assinatura do contrato de refinanciamento de cada estado/município (conforme Quadro 1) e a situação de cada um em abril de 2005, com a relação dívida consolidada/receita líquida real observada na Tabela 13. Assim, realizou-se a simulação utilizando como parâmetro a dívida observada em abril de 2005. Se não houver nenhuma ressalva, considerou-se como critérios aqueles referentes à Lei 9.496/97, ainda que sob a pena de estar superestimando a estoque em 30 anos, já que as demais dívidas freqüentemente apresentam taxas de juros menores. ${ }^{2}$ Distribuiu-se o estoque da dívida do estado de Minas de acordo com a proporção de dívida refinanciada pela Lei 9.496/97 e Proes com juros de 7,5\% (46\% da dívida) e $6 \%$ ( $54 \%$ da dívida), de acordo com base em informações obtidas no site do STN relativas às operações de crédito no segundo semestre de 2004. 
Sintetiza-se o impacto das variáveis independentes sobre os estados com relações dívida/receita mais elevadas a seguir:

- A estrutura da dívida facultou diferentes velocidades de queda, entre outros motivos em decorrência da lógica da tabela Price, segundo a qual uma maior parte das prestações no início se referem aos juros (vide Tabela 3). Estados com maior percentual de dívida renegociada sob a égide da Lei 8.727/93 e que estivessem adimplentes, amortizariam por definição a um ritmo mais intenso. Já quanto maior o percentual da Lei 9.496/97, maior o impacto do IGP-DI.

- O comprometimento de receita de $15 \%$, em alguns casos, também acelerou a amortização da dívida, assegurando de modo geral maior consistência intertemporal às finanças desses estados.

- Estados que conseguiram aumentar expressivamente sua arrecadação também observaram quedas mais acentuadas na relação dívida/receita.

- O impacto do IGP-DI à dívida indexada a juros mais elevados acelerou o crescimento da dívida desses entes da federação.

A conjugação desses efeitos levou ao crescimento da relação dívida/receita em estados como São Paulo e Rio Grande do Sul. Já no caso de Alagoas, isso ocorreu a despeito do maior comprometimento de receita e da diversidade no seu padrão de financiamento.

A trajetória esperada da dívida, dados os parâmetros estabelecidos em 1997 pela Lei 9.496, levava a supor que os estados se defrontariam com uma restrição orçamentária menos rigorosa alguns anos após a assinatura dos contratos, seja em conseqüência da evolução natural da receita, seja pela gradual descompressão decorrente da redução do comprometimento da receita para o pagamento das prestações.

Em conseqüência do impacto do IGP-DI sobre o passivo estadual, a trajetória inicial foi deslocada, com o comprometimento significativo das receitas a despeito do cumprimento pelos estados da cláusula de superávit primário. Para os estados mais endividados, entretanto, o comprometimento de receita continuaria elevado (conforme mostra a Tabela 2) e a situação não seria diversa da observa$\mathrm{da}$ atualmente em termos de fluxos de pagamento (somente no que respeita o estoque da dívida).

\section{A QUESTÃO FEDERATIVA}

A discussão do endividamento subnacional remete implicitamente à questão federativa. A renegociação implicou subsídios diferenciados, assim como o impacto do IGP-DI será distinto entre os diferentes estados em decorrência de diferentes volumes e composições de dívida e relações dívida/receita.

A controvérsia em torno da federação freqüentemente se centra em termos 
dos estados. O bailout, negociado por meio da Lei 9.496/97, implicou ônus expressivo para a União. A construção de um arcabouço institucional coerente com o equilíbrio fiscal intertemporal decorre da constatação de que a capacidade de a União arcar com novos desajustes de governos subnacionais se esgotara. Por outro lado, a manutenção da estabilidade institucional é um avanço nas relações federativas. Portanto, a discussão deve ser sobre a viabilidade de se manter as regras tais quais como estão por agora.

$\mathrm{O}$ ajuste em grande medida foi concebido, como tradicionalmente ocorre no Brasil, de modo a minimizar os conflitos através dos reajustes de alíquotas de ICMS. Essa solução permitiu a transformação do déficit em superávit primário primordialmente com o aumento de receitas.

O pagamento das prestações dos estados consubstancia-se no superávit primário dos governos subnacionais. Perfazendo aproximadamente $1 \%$ do PIB, o aporte das esferas inferiores de poder representa uma contribuição significativa no esforço de ajustamento fiscal.

A questão federativa implica um balanceamento de forças entre as diferentes esferas de poder. O rigor da aplicação da lei decorreu também de um esgotamento da União e de sua capacidade da arcar com os desequilíbrios fiscais subnacionais. Se os estados foram afetados pelas alterações no quadro macroeconômico, a repercussão sobre a União foi muito mais significativa. Em Giambiagi e Rigolon (1999) enfatiza-se o subsídio da União para estados decorrente do diferencial entre Selic (considerada como preço médio de captação do governo federal no mercado) e taxa de juros pagas pela maioria dos estados (ou seja, de $6 \%$ a.a.). Supôs-se, então, que a Selic seria decrescente ao longo do tempo, o que era esperado em decorrência do cenário macroeconômico observado na época, atingindo, a partir de $2004,7,5 \%$ a.a. Isso de fato não ocorreu, tornando o subsídio federal potencialmente mais significativo.

O descolamento do IGP-DI do IPCA funcionou como um aumento da taxa de juros (Tabela 8) e aproximou a taxa paga pelos entes da federação ao preço de captação do governo federal, reduzindo o subsídio concedido, como pode ser constatado na Tabela 12, que compara os juros pagos pelos governos estaduais à taxa de juros deflacionada pelo IGP-DI. O ônus do endividamento deve ser distribuído entre as diferentes esferas de poder, se estamos de fato em uma federação. Além do mais, de modo geral, os que tiveram maiores subsídios foram aqueles mais onerados pelo aumento do IGP-DI. 
Tabela 12: Evolução da taxas de juros Selic e dos juros de 6\% ao ano - 1998-2004 Número índice base $1997=100$

\begin{tabular}{lccc}
\hline & $\begin{array}{c}\text { Selic deflacionada } \\
\text { IGP-DI }{ }^{(\text {(a) }}\end{array}$ & $\begin{array}{c}\text { Juros de } \\
6 \% \text { a.a. (b) }\end{array}$ & $(\mathrm{a}) /(\mathrm{b})^{*} 100$ \\
\hline 1997 & 100,0 & 100,0 & 100,0 \\
\hline 1998 & 124,0 & 106,0 & 117,0 \\
\hline 1999 & 139,9 & 112,4 & 124,5 \\
\hline 2000 & 144,4 & 119,1 & 121,2 \\
\hline 2001 & 153,5 & 126,2 & 121,6 \\
\hline 2002 & 161,1 & 133,8 & 120,4 \\
\hline 2003 & 161,8 & 141,9 & 114,1 \\
\hline
\end{tabular}

Nota: ${ }^{1}$ Considerou-se o IGP-DI médio.

Fonte: Bacen.

A justificativa para a redução das prestações ou do montante devido é freqüentemente fundamentada em princípios federativos. No entanto, a questão federativa relativa ao endividamento foi equacionada pela solução contemporizadora gradualmente implementada. A exigência de superávits primários elevados impede a redução da contribuição das unidades da federação sem contrapartida da União, que provavelmente seria compelida a financiar o aumento do superávit através de novos aumentos de carga tributária.

A busca por uma solução que resguarde o comprometimento dos estados com o ajustamento fiscal, sem sufocá-los a ponto de pleitear uma nova renegociação da dívida, romperia definitivamente com um dos principais preceitos da LRF, deve fazer parte da agenda de negociações.

A pressão excessiva sobre governos subnacionais fortalece o pleito dos governadores. E o risco de se discutir no Senado qualquer alteração nos contratos decorre da natureza da casa. Responsável pelo equilíbrio federativo, as negociações políticas poderiam levar à revisão dos critérios de refinanciamento para todas as unidades da federação, em prejuízo da União.

O ideal, portanto, seria a busca por uma solução negociada no plano institucional para evitar novas rupturas. A LRF, em seu artigo 35, prevê que não serão permitidas operações de crédito entre entes da federação, vetando, portanto, novos refinanciamentos da dívida subnacional (como se classifica toda e qualquer mudança nos contratos assinados no âmbito do Programa de Reestruturação Fiscal e Financeira).

Inicialmente, se enfatizou o caráter negociado que sempre distinguiu a Federação Brasileira. As leis e as regras devem balizar as relações intergovernamentais, sempre concedendo espaço para que o jogo político se faça presente. A força da prática se impõe regras muito rígidas. $\mathrm{O}$ receio que se tinha com a LRF era exatamente esse. A Resolução do Senado $n^{\circ} 20$, de 2003, e sua interpretação pe- 
la $\mathrm{STN}^{10}$ reforçam os receios de se estabelecer uma legislação muito rígida para regulamentar as relações intergovernamentais. Entretanto, o referencial institucional, ainda que flexibilizado em alguma medida de modo a adequá-lo às contingências do contexto político e econômico, permanece como um avanço em termos de relações federativas.

As reivindicações dos estados com relação ao endividamento decorrem de problemas mais profundos e de difícil solução, e nos remetem à Constituição de 1988. Constituíram-se direitos e deveres sem atrelá-los a um modelo de financiamento. Da descentralização desorganizada, tratada por diversos autores como Operação Desmonte, caminhou-se para a institucionalização das relações federativas através do financiamento co-partilhado induzido pelo Fundef e pela Emenda Constitucional $n^{\circ} 29$ (que trata do comprometimento da receita para o financiamento da saúde), em um contexto de austeridade fiscal promovido pela LRF e pelo Programa de Reestruturação Fiscal e Financeira. Esse conjunto de medidas, se, por um lado, levou à revisão das relações federativas e permitiu uma coordenação do processo pelo governo federal, ${ }^{11}$ por outro, engessou o orçamento estadual. Essas mudanças nas relações federativas foram positivas na medida em que fazem parte de um esforço para tratar as políticas públicas de um modo sistêmico, mas levam a discutir o atual modelo de financiamento. Com base na definição das funções a serem exercidas por cada ente, parte-se em direção da demarcação subseqüente das fontes de financiamento necessárias. ${ }^{12}$ Contudo, não se deve confundir a redefinição do papel de cada esfera de poder com a revisão dos princípios que norteiam a LRF e o Programa de Reestruturação Fiscal e Financeira. O federalismo deveria evitar movimentos de sístole e diástole e buscar caminhar em frente, carregando consigo os avanços alcançados.

Gradualmente, constitui-se um estado federativo mais maduro, no qual convivem um elevado grau de descentralização fiscal e uma crescente capacidade de coordenação do governo central, em um cenário de busca pelo equilíbrio fiscal intertemporal. Ainda há muito a ser feito, mas não se podem desconsiderar as conquistas alcançadas, conquistas estas que vislumbram a possibilidade de romper a dicotomia presente nos movimentos de sístole e diástole que tradicionalmente caracterizaram o federalismo brasileiro, já que se caminha em direção à integração da descentralização e autonomia, o que caracterizaria uma ruptura efetiva com o antigo modelo federativo.

\footnotetext{
${ }^{10}$ Segundo Afonso (2005):

"Guardia passou a detalhar porque se mostrava especialmente preocupado com a interpretação que o Tesouro recentemente deu para a Resolução $\mathrm{n}^{\circ} 40$ do Senado, segundo a qual apenas em 2016 ocorreriam as punições para os entes federativos que não tivessem reduzido suas dívidas segundo a trajetória exigida pela LRF” (Afonso, 2005: 9).

${ }^{11}$ Varsano e Mora (2001), e Oliveira (2003).

${ }^{12}$ Prado (2003)
} 


\section{CONSIDERAÇÕES FINAIS}

A dívida subnacional no Brasil desde a década de 80 configurou-se como um problema nacional. Recorrentes refinanciamentos, com a transferência do desequilíbrio para a esfera federal, ocorreram sucessivamente (em 1989, 1993 e, por fim, em 1996/7). A dívida em 1996 superava os 16\% do PIB, requerendo uma solução definitiva.

Em resposta à demanda dos governos estaduais, formatou-se o Programa de Reestruturação Fiscal e Financeira. Mais do que uma simples renegociação da dívida, inicia-se a constituição de um aparato institucional que visava o equilíbrio fiscal intertemporal. Posteriormente, fortalecido pela LRF, o controle ao endividamento proposto pelo Programa adquire um caráter institucional.

As principais medidas do Programa levaram os governos subnacionais a contribuir positivamente com o esforço de ajustamento fiscal do setor público consolidado, permitiram integralizar o ciclo das privatizações com a venda das distribuidoras de energia elétrica e induziram a venda e/ou liquidação dos bancos estaduais.

A prática reiterada, apoiada em parâmetros claros e metas bem definidas, permitiu a revisão efetiva das relações federativas. E essa prática reiterada, não obstante o espaço reservado para o jogo político, decorreu, em última instância, da exigência macroeconômica de superávits primários.

O resultado fiscal das unidades da federação foi excelente, revertendo o déficit e contribuindo de modo expressivo para o esforço empreendido pelo setor público consolidado. Entretanto, não obstante o pagamento das prestações do refinanciamento pelos governos estaduais, a trajetória dívida/receita líquida real frustrou as perspectivas delineadas em contrato, de redução contínua. Pode-se atribuir isso ao descolamento do IGP-DI dos demais índices de preço ao consumidor, conseqüência do efeito da desvalorização cambial sobre o indexador.

O descolamento do indexador da dívida (IGP-DI) do IPCA, na prática, significou um acréscimo percentual da taxa de juros. Por outro, a frustração das expectativas quanto ao crescimento do PIB restringiu a magnitude do ajuste. A conjugação desses dois fatores implicou uma redução do ritmo de queda da dívida.

Com uma taxa de crescimento superior ao PIB, a receita compensou, em alguma medida, o desempenho medíocre da economia (arrefecendo o impacto dessa variável sobre o modelo) e evitou um descolamento mais significativo na relação dívida/receita líquida real.

Em suma, pode-se dizer que:

- As situações realmente graves são aquelas que combinam elevado estoque de dívida, altas taxas de juros e comprometimento de receita relativamente baixo. Em alguns casos, a trajetória da dívida tende a divergir. Quando isso acontece, não há limite que seja suficiente para acomodar a situação.

- O descolamento do IGP-DI do IPCA afetou negativamente o estoque de dívida, mas sua repercussão tende a se diluir ao longo do tempo. 
- O crescimento da economia cumpre um papel fundamental para o equacionamento do passivo estadual. O maior dinamismo da economia reduz o esforço relativo a ser feito pelos entes da federação mais endividados.

Como os estados e municípios não têm um comprometimento maior com a estabilidade macroeconômica, o seu enquadramento aos limites impostos pela busca de equilíbrio fiscal intertemporal depende de imposições legais. Daí a importância da LRF para a manutenção do equilíbrio intertemporal das finanças públicas. A retomada da atividade econômica, com a aceleração do ritmo de crescimento, tende a reduzir a pressão realizada por prefeitos e governadores para flexibilizar as regras do Programa de Reestruturação Fiscal e Financeira e da LRF, e afasta a possibilidade de impugnação do aparato institucional constituído para conferir às relações federativas maior consistência.

\section{REFERÊNCIAS BIBLIOGRÁFICAS}

AFONSO, J.R.R. (1989) Reforma Constitucional e Endividamento Público de Estados e Municípios: breves notas. Julho, Mimeo.

(1989b) Endividamento Público Estadual e Municipal: evolução recente e perspectivas da nova ordem constitucional. Dezembro, Mimeo

(1992) Aspectos conceituais das relações financeiras intergovernamentais. Estatísticas Econômicas, v. 22, n. 1, p. 5-34. São Paulo, jan./abr.

ALMEIDA, A. O. (1996) Evolução e crise da divida pública estadual. Rio de Janeiro: IPEA (Texto para Discussão, 448).

BEVILAQUA, A. (2000) State Government Bailouts in Brazil. Rio de Janeiro: PUC (Texto para Discussão 421).

LOPREATO, F.C. (2003) Colapso das Finanças e a Crise da Federação. São Paulo, Editora da Unesp. MORA, M.(1996) Processo de endividamento dos estados: problemas e limites à descentralização $e$ à autonomia. Rio de Janeiro: UFRJ (Dissertação de Mestrado).

(2002) Federalismo e Dívida Estadual no Brasil. Rio de Janeiro: IPEA (Texto para Discussão, $866)$.

(2004) A Resolução $n^{\circ}$ 20, de 2003, do Senado e os Limites ao Endividamento dos Estadose Municípios. Rio de Janeiro: IPEA (Nota Técnica; Boletim de Conjuntura IPEA v. 64).

NASCIMENTO, E.R.; DEBUS, I. (2002) “Entendendo a Lei de Responsabilidade Fiscal” in www.stn.fazenda.gov.br

REZENDE, F. (1982) Autonomia politica e dependência financeira: uma análise das transformações recentes das relações intergovernamentais e seus reflexos sobre a situação financeira dos estados. Pesquisa e Planejamento Econômico, v. 12, n. 2, p. 489-540, ago.

OLIVEIRA, F. (org.) (2003) Descentralização de Federalismo Fiscal no Brasil - Desafios da Reforma Tributária. Fundação Konrad Adenauer.

GIAMBIAGI, F.; RIGOLON, F. (1999) “A Renegociação das Dívidas e o Regime Fiscal dos Estados” in GIAMBIAGI, F.; MOREIRA, M. (org.) A Economia Brasileira nos Anos 90, BNDES.

SIMONSEN, M.H. (1995). O Princípio Federativo no Brasil in Reforma Fiscal: coletânea de estudos técnicos, volume II. São Paulo, Dórea Books and Art.

VARSANO, R.; MORA, M. (2001) Fiscal decentralisation and subnational fiscal autonomy in Brazil: some facts of the nineties. Rio de Janeiro: IPEA (Texto para Discussão, 854).

WERLANG, S.R.C.; FRAGA, A. (1995) Os Bancos Estaduais e o Descontrole Fiscal: alguns aspectos (pp. 265-275). Revista Brasileira de Economia; vol. 49 nº 2, abril/junho, Rio de Janeiro. 